\title{
What an Ounce of Prevention can do for your Practice
}

\author{
Maggie Green and Brian Gomes
}

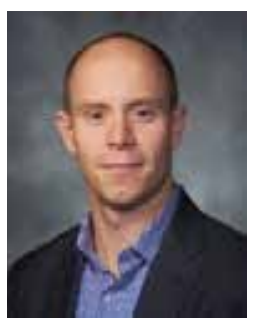

Brian Gomes is the President and Chief Executive Officer of BMS Canada Risk Services Ltd. (BMS Group). He works with many of the country's largest healthcare associations to design and provide customized member insurance programs for over 300,000 Canadian regulated health professionals. Brian has more than a decade of industry knowledge and experience and is frequently consulted to discuss and present on the topic of liability and group risk structures. With several designations, he is considered a national and global expert in the field of medical malpractice and professional liability.

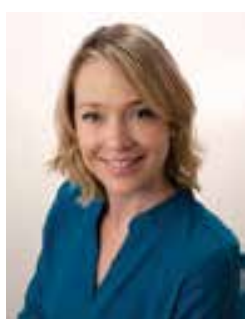

Maggie Green is a registered healthcare professional with a Masters in Healthcare Quality, Risk and Safety, Maggie has over a decade of experience in the healthcare sector. She is a frequent speaker on professional liability, risk management, patient safety, and medico-legal trends in practice. As National Practice Leader for BMS Group, Maggie delivers customized claims and risk management services to healthcare organizations and their members.

$\Lambda \mathrm{s}$ an optometrist, you require professional liability insurance in order to register with

- $y$ your regulatory College. We all know that. But when you purchase your coverage, do you think about why you need it, and how important it really is to the future of your practice? Do you know the details of the insurance you are purchasing? Are you sure you're adequately covered and that you have the appropriate limits in place to respond to a claim?.

Insurance and liability are complex subjects as are the offerings and policies that support them. It is important that you understand the differences between the different insurance options available in order to identify the most appropriate coverage for your practice circumstances. Although insurance is something we hope we never need, it is important to ensure we have the right coverage in place before we actually need it.

\section{Professional Liability Insurance (PLI):}

Regular interaction with patients is a consistent part of any optometric practice and is a daily occurrence. With this in mind, you may face situations where your patients look to hold you responsible for injuries they deem to have received.

Professional Liability insurance (PLI) protects you against liability or allegations of liability for injury or damages that have resulted from a negligent act, error, omission, or malpractice that has arisen out of your professional capacity as an optometrist. Regulatory bodies of optometry require that every licensed optometrist who provides services, whether in a paid or volunteer capacity, be covered by professional liability insurance. PLI protects optometrists by ensuring that your legal defence is coordinated and paid for if a claim is made against you. Your PLI also covers the cost of any patient compensation, or damages. This means that your patients are also protected; because having PLI means that money is in place to compensate them for valid claims.

While your regulatory body requires that you hold professional liability insurance, there are also other factors to consider: Are you a business owner? Do you have employees? Do you have contents to protect? If so, you should consider supplementing your individual Professional Liability Insurance with other coverage to protect your business name, property and contents. 


\section{Business Professional Liability Insurance:}

Business PLI provides a separate limit of liability to protect your business assets in the event that your business name is included in a statement of claim or lawsuit. In the event of an incident, the patient will most likely name not only the individual optometrist, but also your business as the larger provider of services. Business owners should consider purchasing Business PLI if other optometrists (for example, co-owners, employees, associates) are billing under the business name. Please note that coverage should be purchased by one individual on behalf of all business owners, employees, and /or the business entity.

If you work independently or are a sole proprietor with no other optometrists billing under your business name, your CAO individual PLI policy will automatically extend to cover your business name.

Note that for the purposes of the CAO policy, you do not need to purchase Business PLI if your regulated health professional staff consists exclusively of opticians, nor do you need to purchase Business PLI for administrative or support staff.

\section{Commercial General Liability Insurance (CGL):}

Commercial general liability (CGL) insurance protects you against claims arising from injury or property damage that you (or your business, including your staff) may cause to another person as a result of your operations and/or premises. For example, a patient may fall and injure themselves on a wet floor in your office and look to hold you or your business responsible (they have experienced a bodily injury as a result of your premises). That's why CGL is so commonly referred to as "slip and fall" insurance.

CGL coverage is recommended for optometrists who own or operate clinics. This coverage is also recommended for independent practitioners who contract out their services or bill under their business name. As an example, if you are an independent contractor and accidentally cause damage to the property in which you are working, the property owner may look to hold you responsible for compensating them for the costs of repairs. Your CGL policy would respond under these circumstances.

\section{Property Coverage, Crime Coverage, Clinic/Business Package:}

Property Coverage and Crime Coverage protect your business and the contents within from losses associated with property damage (such as fire) and crime. Property Coverage insurance protects against damage to property, including professional equipment, and loss of revenues caused by an interruption of business activities arising from an insured loss. Crime Coverage insurance protects against financial loss due to dishonesty, fraud, or theft of money, securities or other property owned by the business/office.

The CAO program offers a Clinic/Business Package, which includes Property Coverage, Crime Coverage, and CGL insurance. Alternatively, members are able to purchase stand-alone CGL insurance.

Now that you are familiar with the professional liability and business insurance options available, you can use the following hierarchy chart to assist in identifying the insurance coverage that may best suit your practice circumstances.

Please note that this chart provides an outline of common practice scenarios only and does not include all possible professional and business structures. It provides an initial framework for decision-making but should not be considered comprehensive broker advice, nor should it be relied upon as such. You should always speak with an insurance professional at BMS Group to determine the most appropriate coverage for your specific practice circumstances.

Please note that this article is provided for general information purposes only and does not constitute professional legal or broker advice. Please speak with an insurance broker at BMS Group to discuss any questions you may have about your existing insurance coverage or to seek advice on your specific insurance needs. 


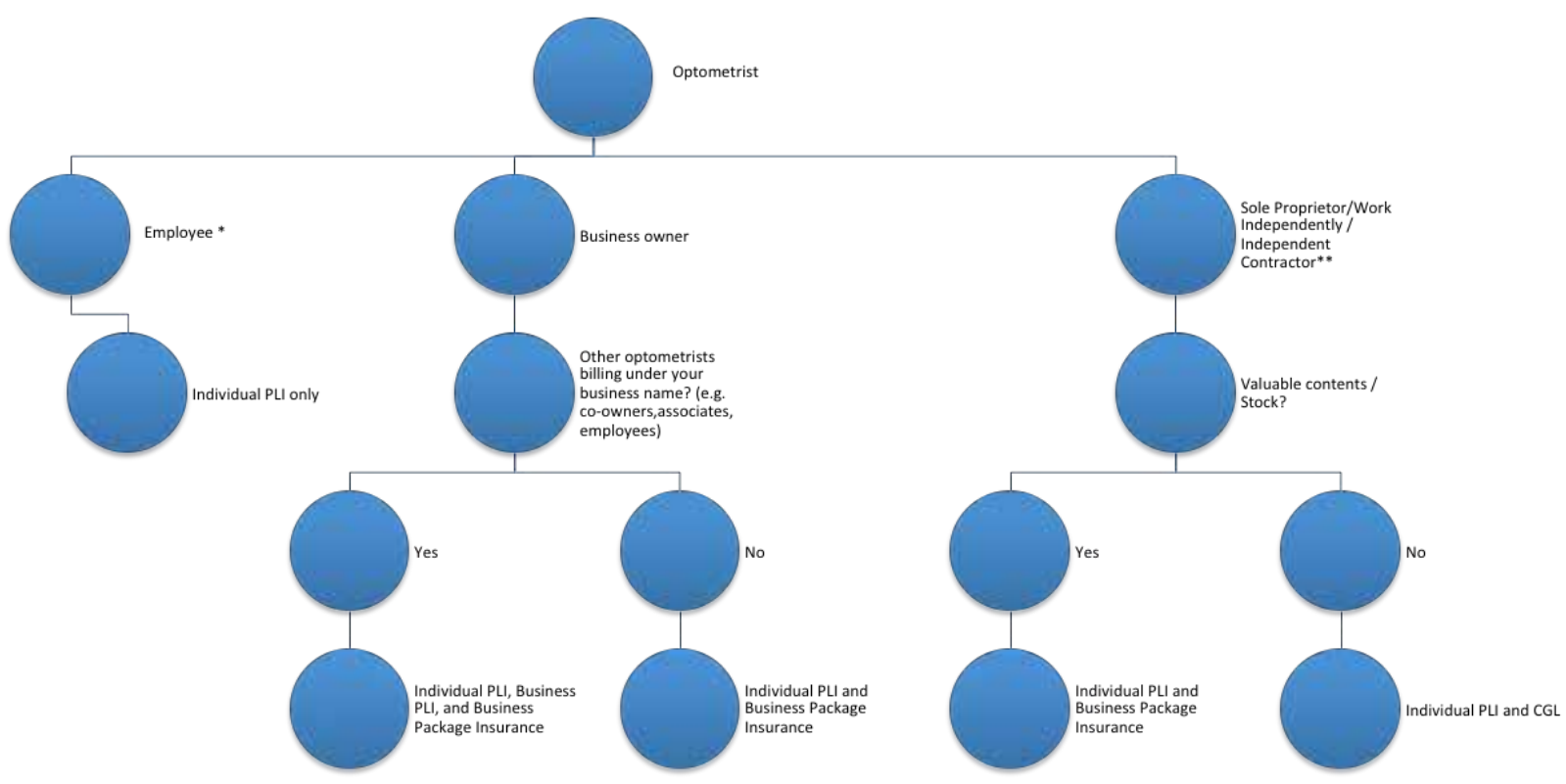

* billing under your employer's business name

** billing under your own business name; no other optometrists billing under your business name

Do you have more questions surrounding your professional liability and business insurance protection?

That's a good thing!

Professional liability protection and insurance are complex areas.

This is why we invite you to contact BMS Group at 1-844-517-1371 or cao.insurance@bmsgroup.com if you have any questions about the CAO insurance program, or to discuss your individual liability or business protection needs.

Find out more about the different insurance coverages here: www.cao.bmsgroup.com.

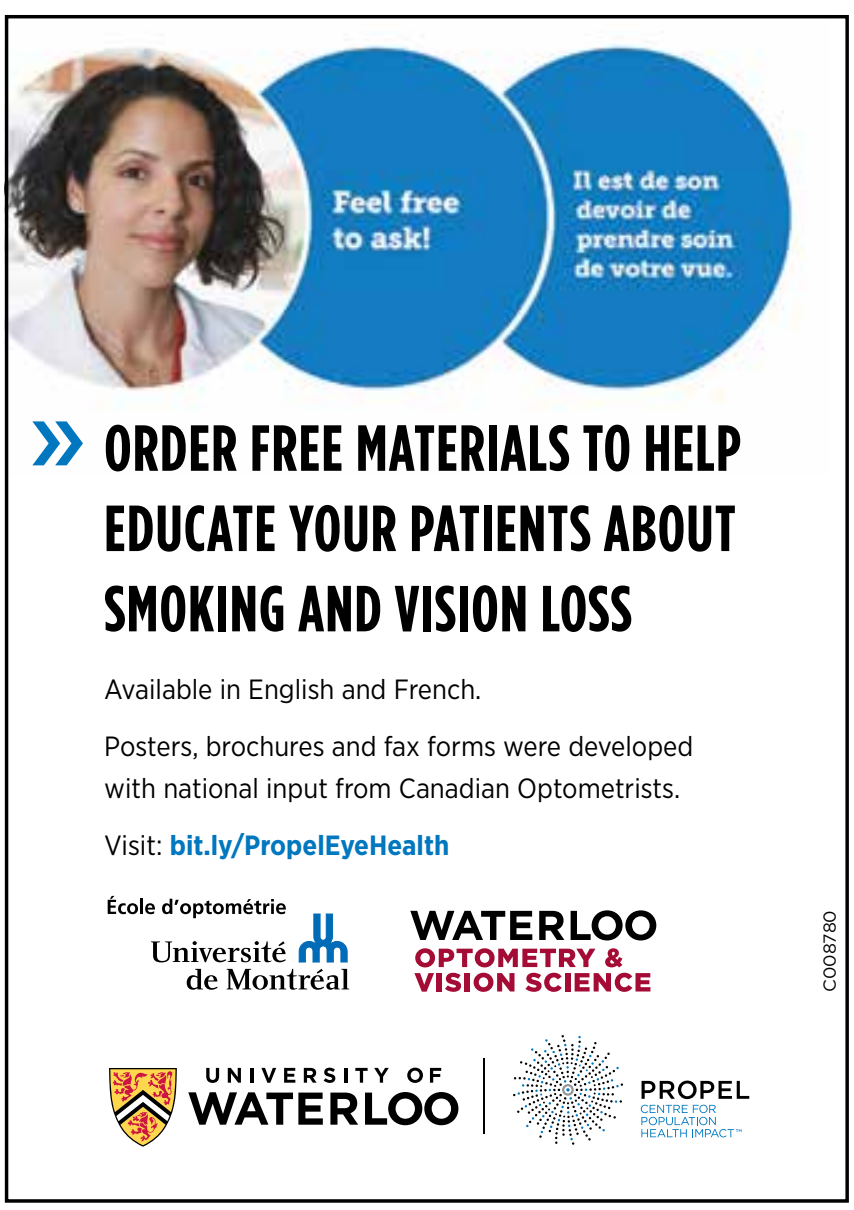

